the present ones which suggest the existence of a photochemical reaction between DNA and bilirubin are somewhat disquieting, particularly when one considers that mutagens and chemical carcinogens derive their biologic activity from the ability to react with DNA. Our results suggest that phototherapy of neonates is a complex process which may generate a number of potentially dangerous genetic side effects.

\section{SUMMARY}

The widespread use of phototherapy in the treatment of neonatal jaundice is causing concern because little information is available on its effects on subcellular structure and function. The present study deals with the effects on the macromolecular structure of DNA illuminated in the presence of bilirubin. The results indicate a bilirubin-induced photodegradation of this biopolymer.

\section{REFERENCES AND NOTES}

1. Behrman, R. E., Brown, A. K., Currie, M. R., Hastings, J. W., Odell, G. B., Schaffer, R., Setlow, R. B., Vogl, T. P., Wurtman, F. J., Anderson, R. J., Kostkowski, H. J., and Simopoulos, A. P.: Preliminary report of the committee on phototherapy in the newborn infant. J. Pediat. 84: 135 (1974).

2. Committee on Environmental Hazards: The susceptibility of the fetus and child to chemical pollutants. Pediatrics, 53 (suppl. II) (I974).

3. Department of Health, Education and Welfare Publication No. (National Institutes of Health) 74-570, National Cancer Program, Digest of Scientific Recommendations for the National Cancer Program. (United States Department of Health, Education and Welfare, National Institutes of Health, 1974).

4. Department of Health, Education and Welfare Publication No. (National Institutes of Health) 74-569, National Cancer Program, The Strategic Plan,
January 1973 edition. (United States Department of Health, Education and Welfare, National Institutes of Health, 1974).

5. Eigner, J.: Moleculat weight and conformation of DNA. Methods Enzymol., 12B: 386 (1968).

6. Mandel, M., and Marmur, J.: Use of ultraviolet absorbance-temperature profile for determining the guanine plus cytosine content of DNA. Methods Enzymol., I2B: 195 (1968).

7. Mandel, M., Schildkraut, C. L., and Marmur, J.: Use of $\mathrm{CsCl}$ density gradient analysis for determining the guanine plus cytosine content of DNA. Methods Enzymol., 12B: 184 (1968).

8. Mrak, E. M.: Report of the Secretary's Commission on Pesticides and their relationship to environmental health. United States Department of Health, Education and Welfare, December 1969 (0-371-074). (United States Government Printing Office Washington, D.C.).

9. Mullinix, K. P., Rosenkranz, S., Carr, H. S., and Rosenkranz, H. S.: Reaction between DNA and N-hydroxyurethan. Biochim. Biophys. Acta, 312: 1 (1973).

10. Rosenkranz, H. S.: Ph.D. dissertation. Cornell University Graduate School of Medical Sciences, 1959.

11. Speck, W. T., Cheng, C. C and Rosenkranz, H. S : In Vitro studies of the effects of light and riboflavin on DNA and HeLa cells. Pediat. Res., 9: 150 (1975).

12. Speck, W. T., and Rosenkranz, H. S.: Base substitution mutations induced in Salmonella strains by visibie light $(450 \mathrm{~nm})$. Photochem. Photobiol., 2l. 369 (1975).

13. Newburyport, Mass.

14. This research was supported by a gift from the George D. Smith Fund, Inc. and by the Division of Cancer Cause and Prevention, National Cancer Institute (Contract No. NO1 CP-33395).

15. Dr. W. T. Speck is the Vivian-Allen Fellow in Clinical Medicine.

16. Dr. H. S. Rosenkranz is a Research Career Development Awardee of the National Institute of General Medical Sciences, United States Public Health Service (5 K3-GM 29, 024).

17. Requests for reprints should be addressed to: W. T. Speck, M.D., Department of Pediatrics, College of Physicians and Surgeons, Columbia University, $630 \mathrm{~W}$. 168th St., New York, N. Y. 10032 (USA).

18. Accepted for publication April 23, 1975.
Pediat. Res. 9: 705-709 (1975)
Corticosteroids

CI-esterase inactivator

glomerular basement membrane

Hageman factor

kallikrein factor $\alpha$-2-macroglobulin

minimal lesion nephrotic syndrome permeability

plasma kallikrein

prekallikrein (Fletcher factor)

\title{
A Study of the Plasma Kinin-generating System in Children with the Minimal Lesion, Idiopathic Nephrotic Syndrome
}

\author{
RONALD J. KALLEN(41) AND SOO-KWANG LEE \\ Department of Pediatrics, University of Chicago-Pritzker School of Medicine and La Rabida Children's Hospital and \\ Research Center, Chicago, Illinois, USA
}

\section{Extract}

Although the precise etiologic incitant of the minimal lesion idiopathic nephrotic syndrome of childhood is not known, it is likely that a host mechanism mediates the permeability alterations of the glomerular capillary wall resulting in massive proteinuria. As a first step in examining the possibility that local kinin release may account for the proteinuria in this disorder, two parameters of the plasma kinin-generating system, plasma prekallikrein and kallikrein inhibitor, were assayed during 27 nephrotic episodes in 21 corticosteroid-responsive children. Plasma kallikrein was assayed by means of its esterase activity on a synthetic arginine ester substrate, $N$ - $\alpha$-tosyl-L-arginine methyl ester (TAMe), after activation of Hageman factor by kaolin. This activity, after subtraction of spontaneous arginine esterase activity (i.e., TAMe esterase activity measured in plasma not exposed to kaolin) is derived from prekallikrein. Plasma prekallikrein activity in 11 normal children was $99.6 \pm 2.9 \mu \mathrm{mol}$ TAMe hydrolyzed $/ \mathrm{ml}$ plasma $/ \mathrm{hr}$ (mean \pm SEM). Kallikrein inhibitor was quantified in arbitrary units. Kalli- krein inhibitor activity in 11 normal children was $0.94 \pm 0.04$ units. During the overt nephrotic syndrome, before initiation of intensive daily corticosteroid treatment, mean values were: prekallikrein, $58.5 \pm 7.24 \mu \mathrm{mol} / \mathrm{ml} / \mathrm{hr}$; and kallikrein inhibitor, $0.35 \pm 0.06$ units. After corticosteroid-induced remission occurred, mean values were: plasma prekallikrein, $118.6 \pm 3.2 \mu \mathrm{mol} / \mathrm{ml} / \mathrm{hr}$; and kallikrein inhibitor, $0.78 \pm 0.03 \mu \mathrm{mol} / \mathrm{ml} / \mathrm{hr}$. Both parameters were again assayed in 14 of the 21 children after complete cessation of corticosteroid treatment. Plasma prekallikrein was normal, 99.6 \pm $4.8 \mu \mathrm{mol} / \mathrm{ml} / \mathrm{hr}$; but kallikrein inhibitor was still somewhat depressed, $0.84 \pm 0.03$ units. A subset of 9 patients had marked depression of plasma prekallikrein to levels less than $20 \mu \mathrm{mol} / \mathrm{ml} / \mathrm{hr}$ and essentially undetectable inhibitor activity. Serum $\alpha-2$ macroglobulin was elevated in nephrotic patients: mean value during relapse, $862 \pm 29 \mathrm{mg} / 100 \mathrm{ml}$; during corticosteroid-maintaining remission, $615 \pm 29 \mathrm{mg} / 100 \mathrm{ml}$. After cessation of corticosteroids, mean serum level was $481 \pm 20 \mathrm{mg} / 100 \mathrm{ml}$. The proportional reduction of plasma prekallikrein and kallikrein inhibitor suggested that an enzyme-inhibitor complex formed in vivo, perhaps at a local 
site of activation in proximity to the glomerular basement membrane. These data suggest that the plasma kinin-generating system may be the host effector mechanism subserving the increased glomerular capillary permeability in the minimal lesion nephrotic syndrome of childhood.

\section{Speculation}

Local activation of the plasma kinin-generating system in close proximity to the glomerular capillary wall may mediate the proteinuria of the minimal lesion nephrotic syndrome. Inhibitors of the kinin-generating sequence may provide effective and rational treatment for children with frequent relapses of the nephrotic syndrome or those corticosteroid-resistant children destined to have a recurrence of the minimal lesion nephrotic syndrome in a renal allograft.

The proximate cause of the massive proteinuria in childhood idiopathic nephrotic syndrome associated with a minimal glomerular lesion ("lipoid nephrosis") is not known. The characteristic change seen on electron microscopy, obliteration of glomerular epithelial cell foot processes, is generally held to be a consequence, rather than the cause of proteinuria (14). It has not been possible to define a role for the usual immune mechanisms in the mediation of proteinuria in this disorder; specifically, prominent immunoglobulin (Ig) or complement deposits along glomerular capillary walls have not been noted (11). The report of glomerular localization of IgE (16) has not been confirmed $(25,29)$. In view of the lack of evidence implicating an immunoglobulin-complement-neutrophilmediated mechanism of glomerular basement membrane damage, it seemed possible that other host-effector mechanisms elaborating a permeability-promoting substance might subserve this role. As a first step in examining this possibility, the behavior of the plasma kinin-generating system was examined in a group of children with this disorder.

The sequence of reactions leading to the generation of bradykinin in plasma is shown in Figure 1. The initial step involves activation of Hageman factor (6), which, in turn, initiates both the coagulation and fibrinolytic systems. Plasmin digests activated Hageman factor, yielding a 28,000 molecular weight fragment (prekallikrein activator) which converts prekallikrein to kallikrein (30). Kallikrein, in turn, cleaves bradykinin from kininogen. Kallikrein also participates in an amplification feedback loop promoting further activation of Hageman factor (1). Bradykinin is rapidly inactivated by plasma kininases. Kallikrein is rendered inactive by formation of a complex with inhibitor proteins, chiefly $\mathrm{Cl}$-esterase inactivator (C1-INA) and $\alpha-2$ macroglobulin.

The purpose of this study was to assay two parameters of the plasma kinin-generating system, viz, plasma prekallikrein and kallikrein inhibitor.

\section{METHODS}

Blood was obtained from 11 normal children and 21 children with 28 episodes of the nephrotic syndrome, during the overt nephrotic phase and after corticosteroid-induced remission of proteinuria. These studies were repeated in 14 of the 21 patients, after cessation of corticosteroid treatment. Patients with renal disease other than lipoid nephrosis were not studied at this time. Venous blood $(4.5 \mathrm{ml})$ was drawn into the second of two plastic syringes and immediately mixed with $0.5 \mathrm{ml} 3.8 \%$ sodium citrate in a plastic tube. The specimen was centrifuged and the plasma separated and analyzed immediately or frozen at $-70^{\circ}$.

The esterase activity of plasma prekallikrein was assayed by the method of Colman et al. (7) employing a synthetic substrate, TAMe-hydrochloride (37). The rate of hydrolysis of TAMe, in terms of methanol released (micromoles per milliliter of plasma per hour), is quantified with reference to a calibration curve prepared with absolute methanol in buffer. Peak esterase activity occurs $1 \mathrm{~min}$ after activation and thereafter declines exponentially (7). The exponential decline is due to interaction of kallikrein with inhibitor protein, mainly CT-INA $(7,8)$. Kallikrein inhibitor is quantified in arbitrary units, wherein 1 unit inhibition equals that amount of inhibitor resulting in 50\% inhibition 5 min after kaolin activation (7).

Serum $\alpha-2$ macroglobulin was measured by radial immunodiffusion using commercially available plates (38). Normal levels are $150-420 \mathrm{mg} / 100 \mathrm{ml}$.

The mean value \pm 1 SEM was computed by standard statistical methods (32). The Student $t$ test (two-tailed test) was employed using a standard program on the Hewlett-Packard 9810 A calculator.

\section{RESULTS}

Plasma prekallikrein and kallikrein inhibitor were assayed in 11 normal children and 21 children with corticosteroid-responsive idiopathic nephrotic syndrome (Table 1). Nine of the 21 nephrotic patients were shown to have lipoid nephrosis on renal biopsy. In 11 normal subjects, results (mean \pm 1 SEM) were: plasma prekallikrein, $99.6 \pm 2.9 \mu \mathrm{mol} / \mathrm{ml}$ plasma $/ \mathrm{hr}$; kallikrein inhibitor, $0.94 \pm$ 0.04 units. These compare favorably with those of Colman et al. (7): plasma prekallikrein $97 \pm 4 \mu \mathrm{mol} / \mathrm{ml} / \mathrm{hr}$; and kallikrein inhibitor, $0.97 \pm 0.03$ units (mean \pm 1 SEM).

Spontaneous arginine esterase activity in our normal subjects was $1.9 \pm 0.4 \mu \mathrm{mol} / \mathrm{ml} / \mathrm{hr}$; this is lower than that reported by Colman et al. (7), $7 \pm 0.8 \mu \mathrm{mol} / \mathrm{ml} / \mathrm{hr}$. This represents a significant difference $(P<0.01)$ for which we have no explanation. However, since this comprises such a small fraction of total arginine esterase activity after kaolin activation, it does not greatly

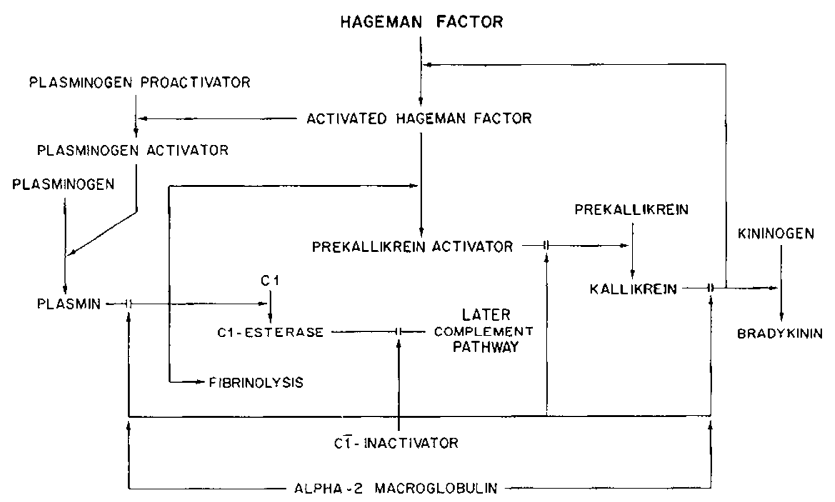

Fig. 1. Pathway of activation of the plasma kinin-generating system. Contact with an altered surface is presumed to activate Hageman factor, thereby initiating the sequence of reactions ultimately leading to cleavage of bradykinin from kininogen by plasma kallikrein. The chief inhibitor of plasma kallikrein is Ci-INA, which also interacts with other plasma proteases.

Table 1. Plasma prekallikrein and kallikrein inhibitor in normal and nephrotic children ${ }^{1}$

\begin{tabular}{lcrr}
\hline & $\begin{array}{c}\text { No. } \\
\text { tested }\end{array}$ & $\begin{array}{c}\text { Plasma } \\
\text { prekallikrein, } \\
\mu \mathrm{mol} / \mathrm{ml} / \mathrm{hr}\end{array}$ & \multicolumn{1}{c}{$\begin{array}{c}\text { Kallikrein } \\
\text { inhibitor, } \\
\text { units }\end{array}$} \\
\hline Normal children $^{2}$ & 11 & $99.6 \pm 2.9$ & $0.94 \pm 0.04$ \\
$\begin{array}{c}\text { During relapse } \\
\text { During remission, }^{1}\end{array}$ & 21 & $58.5 \pm 7.2$ & $0.35 \pm 0.06$ \\
$\begin{array}{c}\text { on prednisone } \\
\text { During remission, } \\
\text { off prednisone }\end{array}$ & 21 & $118.6 \pm 3.2$ & $0.78 \pm 0.03$ \\
& 14 & $99.6 \pm 4.8$ & $0.84 \pm 0.03$ \\
\hline
\end{tabular}

${ }^{1}$ Twenty-one children were studied during 28 nephrotic episodes.

${ }^{2}$ Mean \pm 1 SEM. Prekallikrein data represent net $N$ - $\alpha$-tosyl-L-arginine methyl ester-esterase activity after subtraction of spontaneous activity.

${ }^{3}$ The 14 nephrotic children studied after complete cessation of corticosteroid treatment represent a subset of the 21 children with overt nephrotic syndrome. 


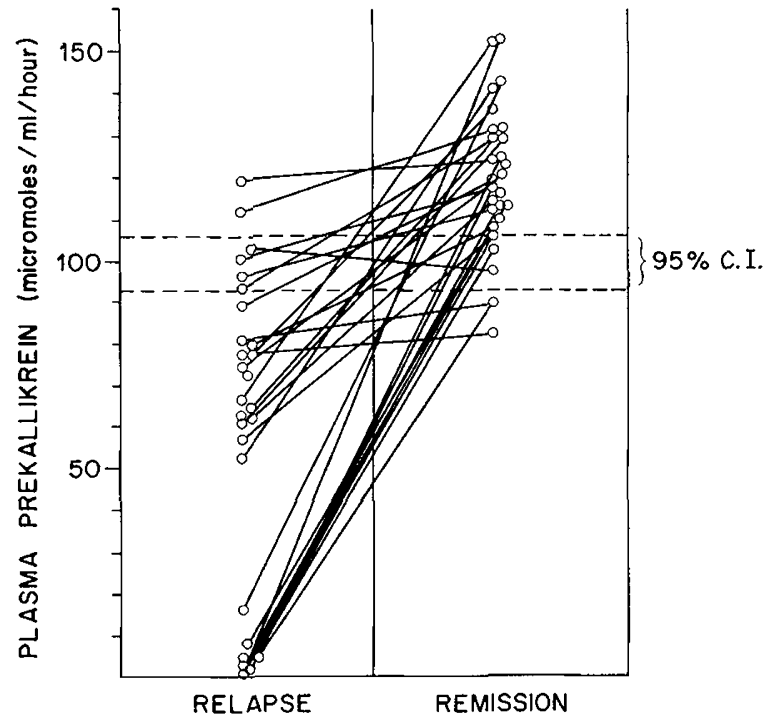

Fig. 2. Plasma prekallikrein in 21 children with 28 nephrotic episodes, before and during corticosteroid-induced remission of proteinuria. Enzyme activity, micromoles of $N$ - $\alpha$-tosyl-L-arginine methyl ester hydrolyzed per milliliter of plasma per hour of incubation, is plotted on the ordinate. The data plotted in the panel labeled relapse refer to children with the overt nephrotic syndrome; the data plotted in the remission panel refer to the same children after corticosteroid-induced remission of proteinuria. -...-: $95 \%$ confidence interval (C.I.) derived from measurements in 11 normal children.

affect the overall results. Spontaneous arginine esterase activity is attributed to the combined action of several arginine esterases in plasma, including kallikrein, thrombin, and plasmin (7).

The 21 patients were studied during 28 episodes of the nephrotic syndrome. The mean age at the time of study was $8.6 \pm 0.8$ years. Serum biochemical measurements reflected the nephrotic syndrome: mean serum total protein, $4.41 \pm 0.11 \mathrm{~g} / 100 \mathrm{ml}$; serum albumin, $1.70 \pm 0.13 \mathrm{~g} / 100 \mathrm{ml}$; and cholesterol, $478 \pm 34 \mathrm{mg} / 100$ $\mathrm{ml}$. Blood urea nitrogen and serum creatinine were normal in all instances. The mean $24-\mathrm{hr}$ protein excretion in 19 patients was 3.0 $\pm 0.5 \mathrm{~g}$. In 24 of the 28 episodes, the patient had experienced a relapse; there were four new patients. In each of the 28 episodes the prednisone dose at the time of study could be established; 18 were not taking prednisone and 10 were taking prednisone in dosages ranging between 5 and $60 \mathrm{mg}$ as a single dose on alternate days.

Mean values of plasma prekallikrein and kallikrein inhibitor in 21 children during an overt nephrotic episode before initiation of intensive daily corticosteroid treatment and after corticosteroidinduced remission are given in Table 1 and Figures 2 and 3. During relapse, plasma prekallikrein is significantly depressed in relation to the mean value in normal subjects $(P<0.001)$, as is kallikrein inhibitor $(P<0.001)$.

After corticosteroid-induced remission occurred in this group of 21 children (generally within $2-3$ weeks of initiating a course of prednisone, $60 \mathrm{mg} / \mathrm{m}^{2} / 24 \mathrm{hr}$ in three or four divided doses), plasma prekallikrein was significantly increased in relation to normal values $(P<0.001)$, and the values during relapse $(P<$ $0.001)$. Kallikrein inhibitor was significantly higher than the value during relapse $(P<0.001)$, but still depressed in relation to the control values $(P<0.005)$

Both parameters were again assayed in 14 of the 21 children after complete cessation of corticosteroid treatment, generally 3-4 months after initiation of high dose daily treatment (Table 1). Plasma prekallikrein was normal, but kallikrein inhibitor was still somewhat depressed, although not significantly different from the mean observed during corticosteroid-maintained remission.

Of particular interest is the subset of nine patients with marked depression of plasma prekallikrein to levels less than $20 \mu \mathrm{mol} /$ $\mathrm{ml} / \mathrm{hr}$ (Fig. 2) and essentially undetectable inhibitor activity (Fig.
3). However, there were no other features of this group of patients that distinguished them from those with moderate reduction in both parameters.

Serum $\alpha$-2 macroglobulin was elevated in nephrotic patients: mean value during relapse $862 \pm 29 \mathrm{mg} / 100 \mathrm{ml}$; and during corticosteroid-maintained remission, $615 \pm 29 \mathrm{mg} / 100 \mathrm{ml}$. After cessation of corticosteroids, mean serum level was $481 \pm 20$ $\mathrm{mg} / 100 \mathrm{ml}$. Elevation of $\alpha-2$ macroglobulin has been noted by others (31)

\section{DISCUSSION}

The depression of prekallikrein and kallikrein inhibitor during the active nephrotic syndrome suggests that the plasma kiningenerating system may play a role in the permeability alterations of the glomerular basement membrane (GBM). Bradykinin may act as the proximate mediator of increased GBM permeability since it is known to increase capillary permeability (26). This mechanism could account for the subtle alterations presumed to occur in the minimal lesion nephrotic syndrome, since even electron microscopy has failed to show evidence of obvious damage to the GBM. In fact, the characteristic alteration on electron microscopy, namely glomerular epithelial cell foot-process obliteration, is believed to be a consequence of excessive filtration of plasma proteins, rather than the cause of proteinuria (14). The ultimate lesion accounting for proteinuria may be beyond the resolution of the electron microscope and could represent subtle conformational changes of the macromolecular structural units of the GBM.

The results reported herein could be explained by the following postulated sequence of events: (l) subtle injury to endothelium or GBM, with contact-activation of Hageman factor by the altered surface; (2) conversion of prekallikrein to kallikrein; (3) local generation of bradykinin in the microenvironment of GBM; (4) rapid inactivation of bradykinin by kininases and binding of kallikrein by $\mathrm{C} \overline{\mathrm{I}}$-INA; (5) sustained activation of Hageman factor at the local site of injury, repeating the cycle of events of steps $I$ through 4 . The repetition of this sequence may partially deplete plasma levels of prekallikrein and inhibitor, in a manner analogous to the depression of complement in the acute serum sickness model of nephritis in rabbits (10). The constant turnover of kallikrein is probably promoted by its stoichiometric binding with inhibitor molecules $(17,36)$, i.e., as soon as active kallikrein is formed, it is rapidly inactivated. It is likely that kallikrein is bound rapidly to inhibitor since we found little increase in spontaneous arginine esterase activity $(3.3 \pm 0.3 \mu \mathrm{mol} / \mathrm{ml} / \mathrm{hr}$, assayed during 28 nephrotic episodes), suggesting that the active enzyme is not present in plasma in significant quantities.

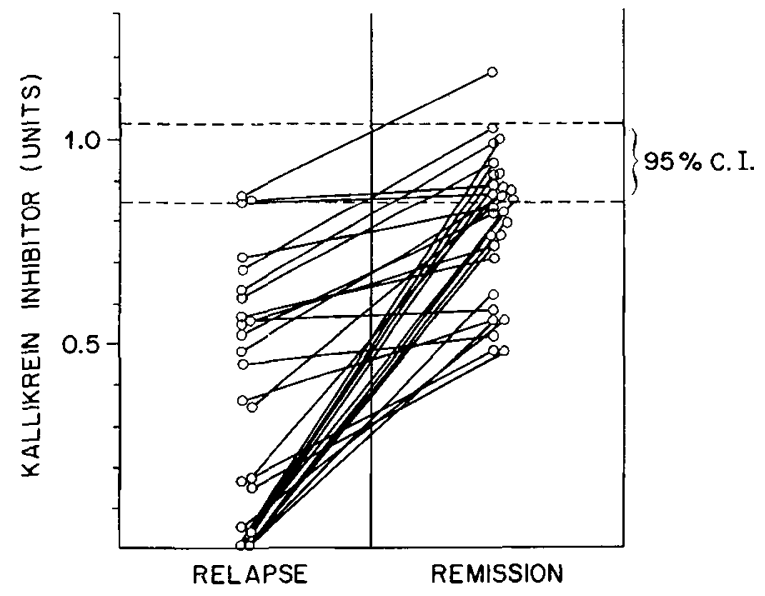

Fig. 3. Plasma kallikrein inhibitor in 21 nephrotic children before and during corticosteroid-induced remission of proteinuria. Values for p!asma kallikrein inhibitor are plotted on the ordinate. The figure is otherwise similar in construction to Figure 2. 
It is possible that kallikrein not only is activated within the fluid phase microenvironment of the GBM, but may also become bound to the GBM in proximity to the site of injury. This is consistent with the recent demonstration of the binding of plasma kallikrein to collagen and the kinin-releasing capability of the surface-bound kallikrein (20).

The above explanation posits that depression of both plasma prekallikrein and kallikrein inhibitor reflects increased turnover and local generation of bradykinin in the absence of a proportional increase in synthesis of new enzyme or inhibitor, thus lowering the plasma level. However, we do not have direct proof for the hypothesis of increased consumption of prekallikrein.

Since the proteinuria in the minimal lesion idiopathic nephrotic syndrome is highly selective $(2,28)$, it seems unlikely that plasma prekallikrein (molecular weight, 120,000) would be found in significant quantities in urine; rather, its depression may well be due to the mechanism indicated above. However, the proposed mechanism remains speculative and studies are currently in progress in our laboratory to establish whether plasma prekallikrein is present in nephrotic urine. Kallikrein inhibitor (mainly Cl-INA) has a molecular weight of 90,000 and plasma levels might be depressed simply as a consequence of urinary losses. However, it is also possible that less inhibitor protein is available for assay by this technic, since some of it may be circulating as an enzyme-inhibitor complex (plasma kallikrein complexed with C1-INA). Formation of such a complex is suggested by the proportional reduction of both kallikrein and kallikrein inhibitor, especially in those patients with essentially undetectable inhibitor and prekallikrein activity of less than $20 \mu \mathrm{mol} / \mathrm{ml} / \mathrm{hr}$.

Although $\alpha-2$ macroglobulin, a polyspecific inhibitor of several plasma proteases, is elevated in the nephrotic syndrome (31), our data fail to show increased inhibitor activity. The failure to detect such activity is not surprising since $\alpha-2$ macroglobulin does not have a prominent effect on the esteratic site of kallikrein assayed by this method (19). The significance of the elevated $\alpha-2$ macroglobulin in the nephrotic syndrome is not known; it may represent a compensatory mechanism for preventing an uncontrolled activation of the kinin-generating system. Alternatively, the elevation of $\alpha-2$ macroglobulin may represent a nonspecific acute phase reaction.

These data clearly suggest that once corticosteroid-induced remission supervened, plasma prekallikrein and kallikrein inhibitor returned to normal levels. Since these patients received corticosteroids at therapeutic dosage levels, the possibility remains that such treatment may have influenced these results. Indeed, Cline and Melmon (4) have shown that plasma of patients treated with prednisone was less susceptible to kinin generation after exposure to glass or autologous granulocytes, and suggested that the site of inhibition was at the interaction between activated kallikrein and kininogen. However, these data have not been confirmed by further in vitro studies which failed to demonstrate a significant inhibitory effect on kallikrein by paramethasone (9) or hydrocortisone (8). Moreover, kinin generation has been shown to be normal in patients receiving anti-inflammatory steroids (13). In view of the return toward normal levels of plasma prekallikrein and kallikrein inhibitor in our patients, our data suggests that intensive daily corticosteroid administration does not interfere with the arginine esterase activity of kallikrein.

Of the 21 patients studied at the time of relapse, before initiation of prednisone at high daily dosage $\left(60 \mathrm{mg} / \mathrm{m}^{2} / 24 \mathrm{hr}\right.$; maximum dose, $60 \mathrm{mg}$ ), 11 were on a maintenance regimen of prednisone varying between 5 and $60 \mathrm{mg}$ as a single dose on alternate days. There was no statistically significant difference of plasma prekallikrein and kallikrein inhibitor between the group receiving a maintenance dose of prednisone and the 10 patients not receiving steroids.

Since Hageman factor has been shown to be decreased in patients with nephrotic syndrome (21), it is possible that, if present in limiting quantities, prekallikrein-to-kallikrein conversion might be depressed as a consequence. Unfortunately, we were unable to carry out concurrent assays of Hageman factor activity in this group of patients. However, a recent study showed that the depression of prekallikrein activity was not due to decreased Hageman factor in the assayed plasma (24), which suggests that the decreased prekallikrein is not simply a secondary consequence of a low level of Hageman factor. Alternatively, the results observed in this study might reflect a reduction in Hageman factor as a consequence of local consumption in accord with the sequence of events postulated above. The depression of Hageman factor is probably not due to urinary losses in view of the recent report which failed to demonstrate Hageman factor in the urine of a patient with the nephrotic syndrome (24).

Activation of the kinin-generating system has been reported in hyperlipoproteinemia type II (3). We do not have a more complete characterization of the type of hyperlipoproteinemia in our patients, but it is known that nephrotics generally have either a type II or type IV pattern (15).

The precise etiologic incitant of lipoid nephrosis is not known but it is possible that subtle damage to the GBM not only leads to contact-activation of Hageman factor (35) and, ultimately, generation of bradykinin, but also initiates the coagulation sequence. The latter is suggested by the finding of platelet thrombi in intimate association with the glomerular capillary wall (12). Nephrotic children may have a hypercoagulable state (27), and a number of alterations of clotting factor levels have been reported (21): depression of Hageman factor and elevation of factor VIII, VII-X complex and fibrinogen. Elevation of fibrin-fibrinogen degradation products in serum has been noted in nephrotic children (33). Platelet counts may be normal, but frequently are increased (18).

The apparent depression of Hageman factor noted in nephrotics (21) may actually be caused by a primary reduction of plasma prekallikrein, by the mechanism outlined above, and consequent inadequate feedback amplification of Hageman factor activation (5). The prolongation of the activated partial thromboplastin time reported in nephrotics (21) is similar to that seen in Fletcher factor (prekallikrein) deficiency (34).

The participation of a "humoral amplification system" (23) may provide the basis for the apparent humoral nature of the recurrence of the nephrotic syndrome in certain patients with lipoid nephrosis receiving a renal allograft (22). If further studies confirm these data, then a more rational search for a specific mode of treatment modulating the kinin-generating system might ensue. Furthermore, a specific mode of therapy resulting from such studies would contribute immeasurably to the management of patients with frequent relapses of the nephrotic syndrome and serious corticosteroid side effects.

It is likely that glomerular capillary wall damage occurs in other forms of glomerulonephropathy, especially when associated with florid histopathologic alterations, such that activation of Hageman factor probably occurs. We are currently extending our studies of the plasma kinin-generating system to such disorders.

\section{SUMMARY}

We postulated that the plasma kinin-generating system may be activated in lipoid nephrosis, with elaboration of a mediator of increased glomerular capillary permeability to plasma proteins. Both plasma prekallikrein and kallikrein inhibitor were depressed in 21 children studied during 28 episodes of the overt nephrotic syndrome. Both parameters returned to normal levels after remission of the nephrotic syndrome and cessation of corticosteroid treatment. These data are consistent with increased turnover of prekallikrein and kallikrein inhibitor in this disorder.

\section{REFERENCES AND NOTES}

1. Austen, K. F.: Hageman-factor-dependent coagulation, fibrinolysis, and kinin generation. Transplant. Proc., 6: 39 (1974).

2. Cameron, J. S.: Histology, protein clearances, and response to treatment in the nephrotic syndrome. Brit. Med. J., 2: 352 (1968)

3. Carvalho, A. C., Vaillancourt, R. A., Cabral, R. A., Colman, R. W., and Lees, R. W.: Clofibrate reversal of accelerated intravascular coagulation in hyperbetalipoproteinemia (Abstract). Clin. Res., 21: 955 (1973). 
4. Cline, M. J., and Melmon, K. L.: Plasma kinins and cortisol: A possible explanation of the anti-inflammatory action of cortisol. Science, 153: 1135 (1966).

5. Cochrane, C. G., Revak, S. D., and Wuepper, K. D.: Activation of Hageman factor in solid and fluid phases. A critical role of kallikrein. J. Exp. Med., 138: 1564 (1973).

6. Cochrane, G. C. and Wuepper, K. D.: The first component of the kinin-forming system in human and rabbit plasma. Its relationship to clotting factor XII (Hageman factor). J. Exp. Med., 134: 986 (1971).

7. Colman, R. W., Mason, J. W., and Sherry, S.: The kallikreinogen-kallikrein enzyme system of human plasma. Ann. Int. Med., 71: 763 (1969).

8. Colman, R. W., Mattler, L., and Sherry, S.: Studies on the prekallikrein (kallikreinogen)-kallikrein enzyme system of human plasma. II. Evidence relating the kaolin-activated arginine esterase to plasma kallikrein. J. Clin. Invest., 48: 23 (1969).

9. Davies, G. E., Holman, G., Johnston, T. P., and Lowe, J. S.: Studies on kallikrein: Failure of some anti-inflammatory drugs to affect release of kinin. Brit. J. Pharmacol., 28: 212 (1966).

10. Dixon, F. J., Wilson, C. B., and Marquardt, H.: Experimental immunologic glomerulonephritis. In: J. Hamburger, J. Crosnier, and M. H. Maxwell: Advances in Nephrology (Year Book Medical Publishers, Chicago, 1971).

11. Drummond, K. N., Michael, A. F., Good, R. A., and Vernier, R. L.: The nephrotic syndrome of childhood: Immunologic, clinical and pathologic correlations. J. Clin. Invest., 45: 620 (1966).

12. Duffy, J. L., Cinque, T., Grishman, E., and Churg, J.: Intraglomerular fibrin, platelet aggregation, and subendothelial deposits in lipoid nephrosis. J. Clin. Invest., 49: 251 (1970).

13. Eisen, V., Greenbaum, L., and Lewis, G. P.: Kinins and antiinflammatory steroids. Brit. J. Pharmacol., 34: 169 (1968).

14. Farqhuar, M. G., and Palade, G. E.: Glomerular permeability. II. Ferritin transfer across the glomerular capillary wall in nephrotic rats. J. Exp. Med., I14: 699 (1961).

15. Fredrickson, D. S., Levy R. I., and Lees, R. S.: Fat transport in lipoproteins-an integrated approach to mechanisms and disorders. New Engl. J. Med., 276: 273 (1967).

16. Gerber, M. A., and Paronetto, F.: IgE in glomeruli of patients with nephrotic syndrome. Lancet, $i: 1097$ (197l).

17. Gigli, I., Mason, J. W., Colman, R. W., and Austen, K. F.: Interaction of plasma kallikrein with the $\mathrm{C}_{1}$ inhibitor. J. Immunol., 104: 574 (1970)

18. Habib, R, and Kleinknecht, C.: The primary nephrotic syndrome of childhood. Pathol. Ann. 6: 417 (1971).

19. Harpel, P. C.: Human plasma alpha-2 macroglobulin. An inhibitor of plasma kallikrein. J. Exp. Med., 132: 329 (1970)

20. Harpel, P. C.: Studies on the interaction between collagen and a plasma kallikrein-like activity. Evidence for a surface-active enzyme system. J. Clin. Invest., 51: 1813 (1972).

21. Honig, G. R., and Lindley, A.: Deficiency of Hageman factor (Factor XII) in patients with the nephrotic syndrome. J. Pediat., 78: 633 (1971).

22. Hoyer, J. R., Raij, L., Vernier, R. L., Simmons, R. L., Najarian, J. S., and
Michael, A. F.: Recurrence of idiopathic nephrotic syndrome after renal transplantation. Lancet, ii: 343 (1972).

23. Hunsicker, L. G., Wintroub, B. U., and Austen, K. F.: Humoral amplification systems in inflammation. In: F. H. Bach and R. A. Good: Clinical Immunobiology (Academic Press, New York, 1972).

24. Lange, L. G., III, Carvalho, A., Bagdasarian, A., Lahiri, B., and Colman, R. W.: Activation of Hageman factor in the nephrotic syndrome. Amer. J. Med., 56: 565 (1974).

25. Lewis, E. J., Kallen, R. J., and Rowe, D. S.: Glomerular localisation of IgE in lipoid nephrosis. Lancet, $i$ : 1395 (1973).

26. Lewis, G. P.: Kinins in inflammation and tissue injury. In: E. G. Erdös: Handbook of Experimental Pharmacology, Vol. 25 (Springer-Verlag, New York, 1970).

27. Lieberman, E., Heuser, E., Gilchrist, G. S., Donnell, G. N., and Landing, B. H.: Thrombosis, nephrosis, and corticosteroid therapy. J. Pediat., 73: 320 (1968).

28. Lines, D. R.: Selectivity of proteinuria in childhood nephrotic syndrome. Arch. Dis. Childhood, 44: 461 (1969).

29. Roy, L. P., Westberg, N. G., and Michael, A. F.: Nephrotic syndrome-no evidence for a role for IgE. Clin. Exp. Immunol., 13: 553 (1973).

30. Revak, S. D., Cochrane, C. G., Johnston, A. R., and Hugli, T. E.: Structural changes accompanying enzymatic activation of human Hageman factor. $J$. Clin. Invest., 54: 619 (1974).

31. Scheinman, J. I., and Stiehm, E. R.: Fibrinolytic studies in the nephrotic syndrome. Pediat. Res., 5: 206 (1971).

32. Snedecor, G. W., and Cochran, W. G.: Statistical Methods, Ed. 6 (lowa State University Press, Ames, Iowa, 1967).

33. Uttley, W. S., Maxwell, H., and Cash, J. D.: Fibrin/fibrinogen degradation products in children with renal disease. Arch. Dis. Childhood, 49: 137 (1974).

34. Weiss, A. S., Gallin, J. I., and Kaplan, A. P.: Fletcher factor deficiency: A diminished rate of Hageman factor activation caused by absence of prekallikrein with abnormalities of coagulation, fibrinolysis, chemotactic activity, and kinin generation. J. Clin. Invest., 53: 622 (1974).

35. Wilner, G. D. Nossel, H. L., and LeRoy, E. C.: Activation of Hageman factor by collagen. J. Clin. Invest., 47: 2608 (1968).

36. Wong, P., Colman, R. W., Talamo, R. C., and Babior, B. M.: Kallikreinbradykinin system in chronic alcoholic liver disease. Ann. Int. Med., 77: 205 (1972).

37. Cyclo Chemical, Los Angeles, Calif.

38. Behring Diagnostics, Somerville, N.J.

39. A preliminary report of these findings was presented at the Midwest Society for Pediatric Research, November 8, 1973, Pittsburgh, Pennsylvania, and the 1974 Annual Meeting of The American Pediatric Society-The Society for Pediatric Research (Pediat. Res., 8: 183 (1974)).

40. Dr. S.-K. Lee was supported in part by the Nephrosis Research Foundation and a Fellowship Award from the Kidney Foundation of Illinois.

41. Requests for reprints should be addressed to: R. J. Kallen, M.D., La RabidaUniversity of Chicago Institute East 65th St. at Lake Michigan Chicago, Ill. 60649 (USA)

42. Accepted for publication April 28, 1975.
Branched chain $\alpha$-ketoacids

fibroblasts

$\alpha$-ketoacid decarboxylation maple syrup urine disease residual decarboxylation activity

\title{
Maple Syrup Urine Disease: Analysis of Branched Chain Ketoacid Decarboxylation in Cultured Fibroblasts
}

\author{
U. WENDEL, ${ }^{(47)}$ H. WENTRUP, AND H. W. RÜDIGER \\ Division of Cytogenetics and Clinical Genetics, Department of Human Genetics, University of Hamburg, Hamburg, \\ West Germany
}

Extract

Kinetic data are presented for the decarboxylation of branched chain $\alpha$-ketoacids (BCKA) by intact human fibroblasts. Cultured cells of normal individuals and nine patients with different clinical pictures of maple syrup urine disease (MSUD) are studied with both $\alpha$-ketoisocaproic acid (2-oxo-4-methylpentanoic acid (KIC)) and $\alpha$-ketoisovaleric acid (2-oxo-3-methylbutanoic acid (KIVA)) 